\title{
Dendritic mRNAs encode diversified functionalities in hippocampal pyramidal neurons
}

\author{
Jun Zhong*1, Theresa Zhang ${ }^{2}$ and Lisa M Bloch ${ }^{3}$
}

Address: ${ }^{1}$ Department for Physiology and Pharmacology, State University of New York Health Science Center at Brooklyn, 450 Clarkson Avenue, Box 29, Brooklyn, NY 11203, USA, ${ }^{2}$ Cold Spring Harbor Laboratory, One Bungtown Road, Cold Spring Harbor, NY 11724, USA and ${ }^{3}$ Agilent Technologies, Integrated Biology Systems, 1 Cragwood Road, South Plainfield, NJ 07080, USA

Email: Jun Zhong* - jzhong@downstate.edu; Theresa Zhang - theresa_zhang@merck.com; Lisa M Bloch - lisa_macera-bloch@agilent.com

* Corresponding author

Published: 17 February 2006

BMC Neuroscience 2006, 7:17 doi:10.1/86/147|-2202-7-17
Received: 08 August 2005

Accepted: 17 February 2006

This article is available from: http://www.biomedcentral.com/I47/-2202/7//7

(C) 2006 Zhong et al; licensee BioMed Central Ltd.

This is an Open Access article distributed under the terms of the Creative Commons Attribution License (http://creativecommons.org/licenses/by/2.0), which permits unrestricted use, distribution, and reproduction in any medium, provided the original work is properly cited.

\begin{abstract}
Background: Targeted transport of messenger RNA and local protein synthesis near the synapse are important for synaptic plasticity. In order to gain an overview of the composition of the dendritic mRNA pool, we dissected out stratum radiatum (dendritic lamina) from rat hippocampal CAI region and compared its mRNA content with that of stratum pyramidale (cell body layer) using a set of cDNA microarrays. RNAs that have over-representation in the dendritic fraction were annotated and sorted into function groups.

Results: We have identified 154 dendritic mRNA candidates, which can be arranged into the categories of receptors and channels, signaling molecules, cytoskeleton and adhesion molecules, and factors that are involved in membrane trafficking, in protein synthesis, in posttranslational protein modification, and in protein degradation. Previously known dendritic mRNAs such as MAP2, calmodulin, and G protein gamma subunit were identified from our screening, as were mRNAs that encode proteins known to be important for synaptic plasticity and memory, such as spinophilin, Pumilio, eEFIA, and MHC class I molecules. Furthermore, mRNAs coding for ribosomal proteins were also found in dendrites.
\end{abstract}

Conclusion: Our results suggest that neurons transport a variety of mRNAs to dendrites, not only those directly involved in modulating synaptic plasticity, but also others that play more common roles in cellular metabolism.

\section{Background}

Neurons are highly polarized cells with extensive processes and thousands of synapses sharing one nuclear genome. The ability to supply specific gene products to a distant synapse is crucial for neuronal functions. Although proteins can be made in the cell body and transported to synapses, local synthesis of proteins from dendritic mRNAs provides an efficient mechanism for delivering synaptic proteins where and when they are needed. It has become evident that mRNAs are transported to the dendrite and translated locally near the synapse following the discovery of synapse-associated polyribosome complexes (SPRCs) [1], and local protein synthesis has been demonstrated following synaptic activation [2-8]. Local protein synthesis is important for longlasting synaptic plasticity and memory, as locally applied protein synthesis inhibitors block branch-specific longterm facilitation in Aplysia neuronal cultures [9], and dele- 


\section{Dissecting}

RNA isolation

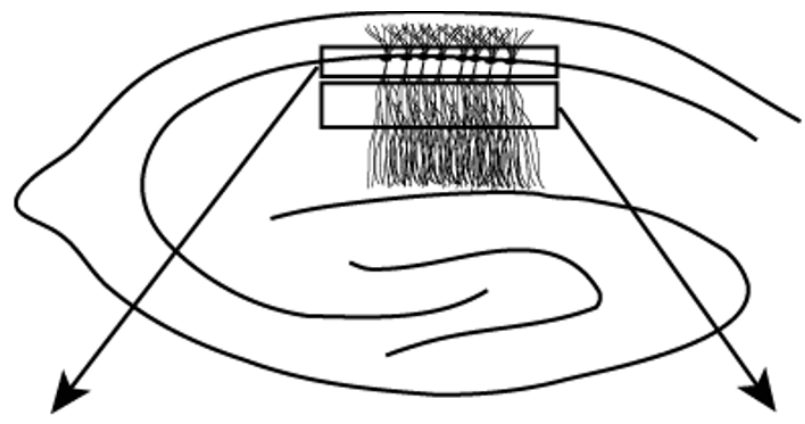

Labeling
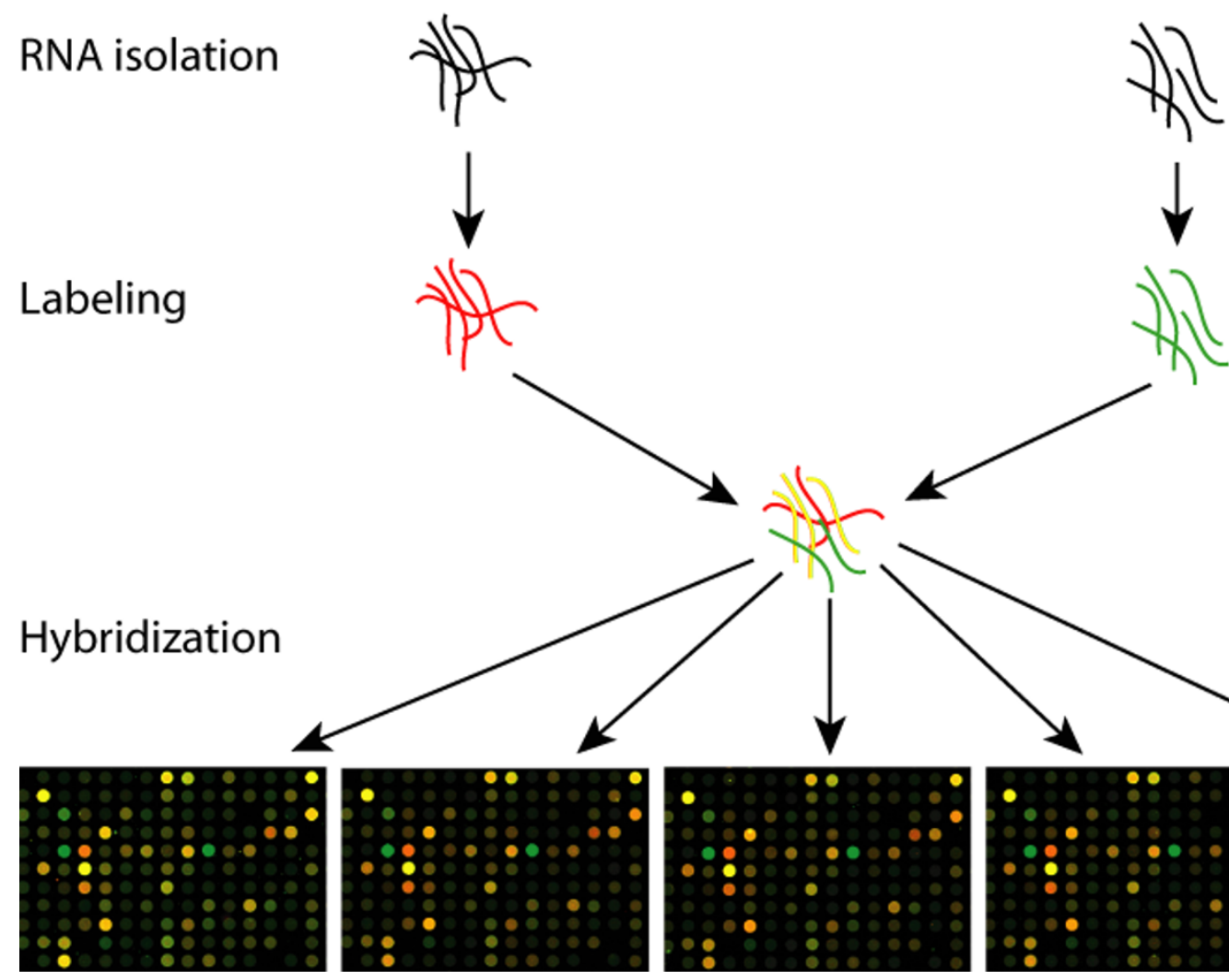

Figure I

A schematic diagram of the experiment. Stratum pyramidale and stratum radiatum were dissected from hippocampal slices of adult rats. Total RNA extracted from each fraction was reverse primed with a T7 promoter-conjugated oligo-d(T) primer and labeled with either Cyanine 3 or Cyanine 5 through in vitro transcription. Equal amount of labeled probes were mixed and hybridized to a set of five replicates of the Agilent $22 \mathrm{~K}$ rat oligonucleotide microarray. Enlarged views of the microarrays are presented showing reproducible hybridization.

tion of the dendritic-targeting element in CaMKII $\alpha$ mRNA impairs synaptic plasticity and memory consolidation [10]. Given the importance of dendritic RNA transport and local protein synthesis, it is surprising that so little is known about the composition of the dendritic RNA pool. It has been estimated that there could be as many as 400 dendritic RNAs in rat hippocampal neurons [11]. So far a few have been shown to localize in dendrites (reviewed in [12-14]). Most of these mRNAs have been identified sporadically through studies on individual genes of interests.
They might not be representative for the whole collection of mRNAs that are transported to dendrites.

Previous attempts to systematically study the collection of transported RNAs have been hindered by lack of bioinformatics tools $[15,16]$. With improvements in bioinformatics and development of commercial microarrays that covers most of the expressed genome, it is now possible to take an unbiased approach to examine the whole dendritic RNA collection. In order to avoid potential contam- 
Table I: The dendritic RNA candidates fall in diversified function groups

\begin{tabular}{|c|c|c|}
\hline Category & number & percentage \\
\hline Receptors, ion channels, and postsynaptic molecules & 12 & $7.8 \%$ \\
\hline Cytoskeleton & 12 & $7.8 \%$ \\
\hline Extracellular matrix, cell adhesion, and immuno-molecules & 31 & $20.1 \%$ \\
\hline Signal transduction and Protein modification & 26 & $16.9 \%$ \\
\hline Translation factors and RNA-binding proteins & 7 & $4.5 \%$ \\
\hline Ribosomal proteins & 25 & $16.2 \%$ \\
\hline Peptide processing and degradation & 12 & $7.8 \%$ \\
\hline Protein transport, membrane trafficking, endocytosis, and exocytosis & 10 & $6.5 \%$ \\
\hline Molecular motor & 1 & $0.6 \%$ \\
\hline Growth factors & 4 & $2.6 \%$ \\
\hline Other & 14 & $9.1 \%$ \\
\hline Total & 154 & $100.0 \%$ \\
\hline
\end{tabular}

ination and differential amplification associated with polymerase chain reaction (PCR), as well as possibly altered properties of neurons cultured in vitro, it would be ideal if one can isolate a significant amount of dendrites directly from the brain. We took advantage of the structural organization of rodent hippocampus - where cell bodies of pyramidal neurons are aligned and separated from dendritic laminas - and dissected out CA1 stratum radiatum that consists of mostly apical dendrites. To avoid contamination from spillover of abundant messages in cell bodies, mRNAs extracted from dendritic laminas was competed with that of cell body layers on a set of microarrays. Only those with increased representations in the dendritic fraction, compared to the cell body fraction were selected as dendritic mRNA candidates. We show here the identification of 154 dendritic mRNA candidates and in situ hybridization of selected messages. In addition to the previously shown classes of mRNAs encoding receptors, cytoskeleton-interacting proteins, and signaling molecules $[12,13]$, our results revealed new classes of mRNAs that are also transported to dendrites. These mRNAs encode factors that are involved in regulating cell adhesion, protein synthesis and degradation, and membrane trafficking.

\section{Results Identification of dendrite-enriched mRNA candidates by microarray study}

Because some messages are expressed at much higher levels than others, direct identification of mRNAs extracted from dendritic laminas would likely be biased towards abundant messages. In addition, the dendritic materials we acquire might be contaminated with small amounts of cell bodies. Therefore, we designed our experiment such that minor contaminations from cell bodies will be competed out using the cell body RNA. Our rationale is that since most mRNAs are restricted to the cell body, an mRNA that is targeted to the dendrite should constitute a higher proportion of the total RNA extracted from dendritic laminas than that from cell body layers. Thus if we co-hybridize equal amount, but distinctively labeled, probes prepared from each sample group to a microarray, we should be able to identify dendrite-enriched RNAs based on the relatively signal strength from each label.

CA1 stratum radiatum and the corresponding stratum pyramidale of selected hippocampal slices were dissected. A total of one microgram RNA was isolated from dendritic laminas, compared to ten micrograms from the corresponding cell body layers, suggesting that dendrites have a lower concentration of RNA than cell bodies. Five hundred nanograms of each RNA sample was labeled and then hybridized on a set of five replicates of a rat oligonucleotide microarray that each contains more than 22 thousand genes. All five slides showed successful and reproducible hybridization (see Figure 1), and three (Additional files 2, 3, 4) were chosen for further analyses using the Resolver software. Data extracted from these slides were compared to each other. Each replicate showed high levels of consistency with others, with correlation coefficients above 0.95 at a P-value of 0.01 . Common features among these data sets were compiled and sorted according to the ratio of dendritic signal versus cell body signal (see Additional file 5). After removing unknown ESTs and entries that are likely due to glial and interneuron contaminations, we generated a list of 154 dendritic RNA candidates that have dendritic signal $v$ s. cell body signal ratios equal or greater than 2 (see Additional file 1).

Among these 154 dendritic RNA candidates, 12 encode receptors, ion channels, and postsynaptic proteins (Table 1 and Additional file 1), including a voltage-gated potassium channel, two chlorine channels, and four $\mathrm{G}$ proteincoupled receptors (GPCRs). Another 14 messages encode proteins that are involved in regulating cytoskeletons, 



\section{Figure 2}

The spinophilin mRNA is transported to dendrites. RNA in situ hybridization on rat brain sections using digoxigen-labeled antisense (A) and sense (B) ribo-probes shows that the spinophilin mRNA is located to the dendritic lamina of hippocampal CAI region (indicated by an arrow). Phase-contrast (C-E) and plain views ( $F-H)$ of in situ hybridization using antisense (C,D,F,G) or sense $(\mathrm{F}, \mathrm{H})$ spinophilin probes also revealed its dendritic localization in cultured hippocampal neurons (indicated by arrows). In addition, an increase in spinophilin mRNA level was observed after $\mathrm{KCl}$ depolarization $(D, G)$.

including a previously known dendritic RNA MAP2 [17] and 12 messages that either directly or indirectly interact with the actin cytoskeleton. Long-lasting modification of synaptic efficacy is usually accompanied by structural changes including outgrowth of existing synapses and formation of new ones [18-20], and such structural changes require modification of the actin cytoskeleton $[21,22]$.
Local synthesis of actin regulators in dendrites could facilitate the control of actin dynamics in response to synaptic activity.

Falling into the next category are 29 messages that encode extra-cellular matrix proteins, cell adhesion molecules, and cell surface molecules normally found in immune 

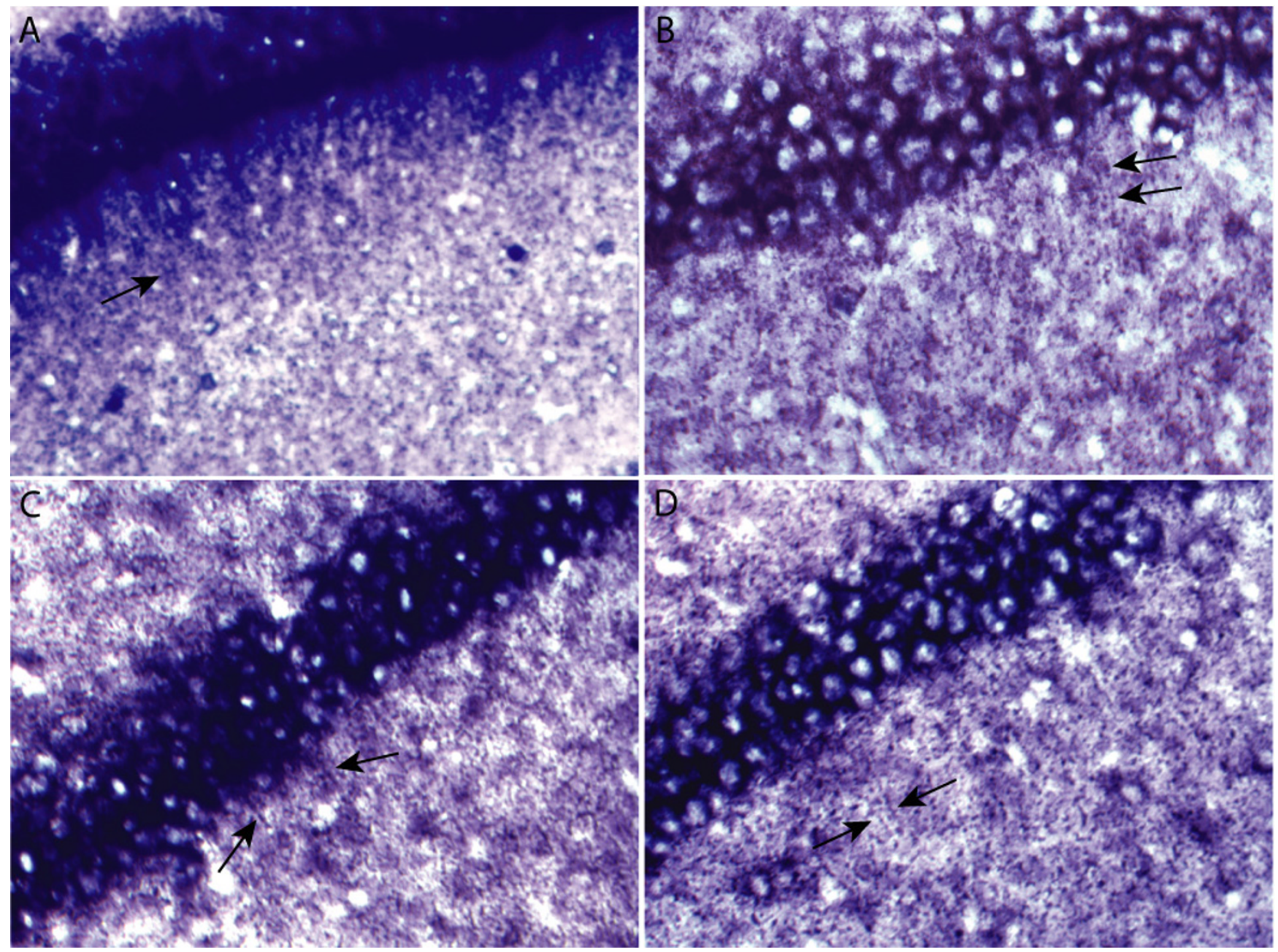

Figure 3

In situ hybridization showing the dendritic localization of the Arc mRNA (A), rat Pumilio 2 mRNA (B), a putative potassium channel I2RF5 mRNA (C), and secretogranin III mRNA (D). Arrows point to punctate staining in the dendritic lamina of rat hippocampal CAI region.

cells. Adhesion molecules have been best studied in axon path finding and synaptogenesis, however, they may also participate in synaptic plasticity in adults brains, which also involves formation of new synapses and elimination of old ones as mentioned above. It was a little surprising to see immune molecules in our dendritic RNA candidate list. However, it has been reported that the Class I MHC molecules are expressed in mature central nervous system (CNS), and are required for activity-dependent remodeling of synaptic connections $[23,24]$. Moreover, detection of Class I MHC proteins in synaptosome preparations suggests that they are enriched at synapses [23]. Our results suggest that mRNAs of Class I MHC molecules are transported and locally translated in dendrites. In addition to Class I MHC mRNAs, our list also contains mRNAs for other immune molecules such as the $\mathrm{T}$ cell receptor beta chain, which was found in the CNS neurons [25].

\section{Signaling molecules that are synthesized in dendrites}

In the next group we have 27 entries representing 26 mRNAs. These messages are involved in intracellular signaling and protein modification. They include two previously known dendritic mRNAs - calmodulin and G protein gamma subunit $[26,27]$. There were two different oligos on the microarray representing this $G$ protein gamma subunit mRNA, both had similar ratios of dendrite $v$ s. cell body signals (2.31 and 2.19), further suggesting consistency in hybridization and data processing. In addition to $G$ protein and the $G$ protein coupled receptors mentioned above in the receptor category, we also have a few other messages involved in G protein signaling. Several molecules involved in cAMP signaling are also found in this group, including cAMP-dependent protein kinase (PKA), anchor protein for PKA (AKAP), adenylyl cyclase 5, and a PKA substrate that is phosphorylated in response to 
GPCR activation. Furthermore, other molecules involved in MAPK signaling pathway, ras signaling, CaMK signaling, and PKC signaling are also present. On the phosphatase side, we have two regulatory subunits and one catalytic subunit of the protein phosphatase 1 (PP1). In addition to these signaling molecules, three other messages encode enzymes that are involved in posttranslational protein modification. These enzymes may be important for the maturation of some locally synthesized proteins in dendrites. Finally, we have an mRNA encoding S6 kinase, which could also be appropriately assigned to the next functional group of RNA translational regulators [28].

Spinophilin is one of the two PP1 regulatory subunits obtained from the screening. It contains an F-actin-binding domain, a PDZ domain, and three coiled-coil structure domains $[29,30]$. Spinophilin is highly enriched in dendritic spines, and it has been suggested to target PP1 to synapses in addition to regulating PP1 catalytic activity [29]. PP1 is an important protein phosphatase that, among many other functions, regulates AMPA channel activity and synaptic strength, and both activities are modulated by spinophilin $[31,32]$. In addition to regulating PP1, spinophilin has been suggested to bundle F-actin and link actin filaments to membranes through its actinbinding domain and PDZ domain [30]. Lack of spinophilin leads to increased spine density as well as altered synaptic transmission [33]. Furthermore, spinophilin has also been shown to interact with $\mathrm{D} 2$ dopamine receptor [34], adrenergic receptors [35], the trans-Golgi network membrane protein TGN38 [36], and rat lin-10 [37]. It also affects GPCR signaling through its interaction with arrestin [38]. To examine whether the spinophilin mRNA is localized in dendrites, we carried out in situ hybridization using a digoxigen-labeled probe for spinophilin. As shown in figure 2, the spinophilin mRNA is present in dendritic laminas in hippocampus. In addition, the spinophilin mRNA is also localized in the dendrite of cultured hippocampal neurons, and its expression level is elevated after $\mathrm{KCl}$ stimulation (Figure 2).

\section{Messages encoding translation factor eEFIA and translational repressor Pumilio are localized in dendrites} Local translation of dendritic mRNAs is modulated by synaptic activities [2-8]. It is not unexpected to see mRNAs encoding translational regulators are translated locally and presumably also regulated by synaptic activities - in dendrites. On top of the list for this category is the eukaryotic translation elongation factor 1 alpha (eEF1A) mRNA, which has a dendrite/cell body signal ratio of 4.27 . It has been shown that the Aplysia eEF1A mRNA can be induced and transported to Aplysia sensory neuron axons upon serotonin treatments $[16,39]$. In addition, the translation of mammalian eEF1A mRNA is regulated by Fragile X mental retardation protein (FMRP) [40], a translational regulator that is required for activity-dependent translation at synapses $[6,8]$. A recent publication suggests that the mRNA for mammalian eEF1A is indeed localized in dendrites and translated locally upon activation [41].

In addition to eEF1A, mRNAs encoding several RNA binding proteins and a ribonuclease also showed enrichments in the dendritic fraction. These molecules may be involved in RNA metabolism including RNA targeting, translation, and degradation. One of these mRNAs encodes a rat homolog of Drosophila Pumilio. Pumilio belongs to a group of maternal factors that determine pattern formation of the Drosophila embryo [42]. It acts together with Nanos to repress the translation of Hunchback mRNA [43-46]. In addition, Pumilio has also been suggested to repress Cyclin B1 mRNA in Xenopus oocytes [47]. Recently, evidences began to emerge suggesting that Pumilio plays important roles in nerve cells as well. In search for memory-related genes in Drosophila, Dubnau et al. looked for genes with altered expression levels after learning and genes of which mutation causes memory defects [48]. Pumilio was pulled out from both screening, suggesting it plays an important role in learning. It has been shown that Pumilio binds to the 3 ' untranslated region (3' UTR) of eIF4E mRNA and regulates its translation at the Drosophila larval neuromuscular junction (NMJ) [49]. The level of Pumilio determines postsynaptic eIF4E protein levels, the number and morphology of NMJ boutons, as well as the dendrite morphology of Drosophila periphery neurons $[49,50]$. In addition, Pumilio also modulates neuronal excitability through regulating the mRNA of a voltage-dependent sodium channel [51].

Our result suggests that Pumilio mRNA is targeted to the dendrite, with a dendrite/cell body signal ratio of 2.15. This is in agreement with its crucial roles in regulating other synaptic messages and in maintaining both synapse morphology and synaptic function. In situ hybridization confirmed that Pumilio mRNA is localized to the dendrite, as manifested by punctate staining in the dendritic lamina of hippocampal CA1 region (Figure 3B). We observed similar punctate staining for several dendritic RNAs, including the Arc mRNA (Figure 3A). These puncta were not due to glial or interneuron staining, as a glia-specific probe and an interneuron-specific probe resulted in very different staining patterns (data not shown). We are not certain whether these puncta are related to the RNA granules reported by other groups [52-56], and we were not able to correlate the size of these puncta with that of RNA granules, as the former were resulted from antibody staining and enzymatic color reactions. 



Figure 4

Ribosomal protein L9 mRNA is localized in dendrites and is induced by kainate seizure. In situ hybridization using a sense (A) and an antisense (B,C) probe specific for $L 9 \mathrm{mRNA}$, showing L9 mRNA is localized in dendrites of pyramidal neurons (indicated by arrows), in addition to its localization in interneuron and glial cell bodies (indicated by arrowheads). An increased level of L9 mRNA has been observed in brain slices of kainic acid treated animals (C).

\section{Peptide processing and protein degradation}

A key advantage of protein synthesis in dendrites is that it allows a tighter control of local protein levels at synapses, which cannot be achieved without a counter-balancing mechanism that removes excessive or damaged proteins. The ubiquitin-proteasome has been shown to be important for long-term facilitation in Aplysia [57-60], and its components are found in the dendrite of rodent CNS neurons [13,61]. In human, loss-of-function of an E3 ubiquitin ligase E6-AP causes Angelman's syndrome, a disease that is associated with mental retardation [62]. Mice carrying a maternal mutation of this E3 ubiquitin ligase gene exhibit defects in synaptic plasticity and learning [63]. We found that four mRNAs that encode putative E3 ubiquitin ligases and their interacting proteins are enriched in the dendritic fraction, including one responsible for CharcotMarie-Tooth disease type $1 \mathrm{C}$. Also found in this category are mRNAs of a putative regulatory subunit of the $26 \mathrm{~S}$ proteasome and several proteases. These molecules could participate in overall protein turnover or targeted degradation of specific proteins, as evidenced by targeted degradation of the regulatory subunit of PKA in Aplysia sensory neurons [57]. In addition, ubiquitination could also serve as a signal for endocytosis of membrane proteins like the AMPA receptors, and thus directly modulates the electrophysiological property of synapses [64,65]. Finally, some of these proteases could participate in peptide processing, and may be important for the maturation of some locally synthesized peptides.

\section{Membrane trafficking and protein transport}

Membrane proteins such as adhesion molecules and receptors have to be integrated into synaptic sites, regardless whether they are synthesized in the cell body or in the dendrite. Thus factors involved in membrane trafficking must be present in dendrites. In addition, it is known that levels of some cell surface proteins such as apCAM and AMPA receptors are regulated in activity-dependent manners through endocytic and exocytic pathways [66-68], suggesting that membrane-trafficking factors must be regulated by synaptic activities as well. Our results indicate that mRNAs encoding regulatory factors for membrane trafficking and vesicle transport are present in the dendrite, including several ADP-ribosylation factors. We show here the dendritic localization of secretogranin III mRNA, which encodes a granin protein involved in the secretory pathway (Figure 3D). Furthermore, the mRNA of a myosin regulatory light chain was also isolated from our screening. Myosin is an actin-dependent molecular motor enriched at postsynaptic densities [69]. It may be involved in the transport of RNA granules from the dendritic shaft to dendritic spines [70]. Our result suggests that myosin mRNA is likely targeted to dendrites and translated locally.

\section{Messages that encode ribosomal proteins are present in dendrites}

In an effort to identify transported mRNAs in Aplysia sensory neurons, Moccia and colleagues sequenced a cDNA library constructed from Aplysia sensory neuron processes [16]. They showed by in situ hybridization that several ribosomal protein mRNAs are present in Aplysia neurites [16]. This is surprising since ribosomal subunits are thought to be assembled in the nucleus [71]. The authors suggested that locally synthesized ribosomal proteins can be added onto partially assembled ribosomal subunits in neurites, and they may be used to replace existing ribosomal proteins in already assembled subunits [16]. In a separate study, Sung et al. also found two mRNAs encod- 
ing ribosomal protein S29 and L18a in rat synaptosomes [72]. We have identified 25 ribosomal protein mRNAs in our dendritic RNA list, including L8, S15, S16, and S29 that were identified as transported mRNAs in previous studies $[16,72]$. To examine whether ribosomal protein mRNAs can be transported to dendrites of mammalian neurons, we carried out in situ hybridization using a probe specific for ribosomal protein L9 mRNA (Figure 4). We observed L9 mRNA signals in dendrites, in addition to the staining of interneuron and glia cell bodies (Figure 4B). Furthermore, we also found that the L9 mRNA can be induced by kainic acid treatment of the animal prior to fixing the brain for in situ hybridization (Figure 4C), suggesting there is an increased demand for L9 protein upon neuronal activation.

\section{Discussion}

We show here the identification of 154 dendritic mRNA candidates in rat hippocampal neurons by comparing the RNA contents of CA1 stratum radiatum and stratum pyramidal. This number does not include 142 unknown ESTs (not shown). In addition, the microarray we were using contains only about two-third of the expressed rat genome. Considering these factors, our number could fall into the same range as the previous estimate of 400 dendritic RNAs by Eberwine and colleagues [11]. These 154 dendritic mRNA candidates represent a broad range of mRNAs that encode diversified functionalities, including receptors and signaling molecules that regulate the electrophysiological properties of the synapse, adhesion molecules and actin cytoskeleton that maintain the structural integrity of the synapse, molecular motors that transport cargos between synapses and cell soma, as well as factors that regulate mRNA translation, protein modification, membrane trafficking, and protein degradation. Clearly, this list does not include all dendritic mRNAs in hippocampal neurons due to technical limitations. Nonetheless, our results provided a much broader view of the dendritic mRNA pool in hippocampal neurons of adult rat brain, and may contribute to our understanding of the in vivo biology of these mature neurons.

\section{Independent mechanisms that target both spinophilin mRNA and protein to dendrites}

Our results indicated that the mRNAs of spinophilin, Pumilio, eEF1A, and MHC class I are localized in dendrites. These messages have been shown to play important roles in synaptic plasticity and memory, and their protein products have been found at synapses. We suggest that targeted transport of these messages in dendrites may contribute to the synaptic localization of their protein products.

It has been shown that the actin-binding domain of spinophilin is necessary and sufficient for targeting its protein to dendritic spines [73]. Taken together with our findings, these results suggest that there may be redundant mechanisms of targeting both the mRNA and the protein to ensure sufficient delivery of spinophilin to synapses, a scenario that is analogous to CamKII $\alpha$. Deletion of the dendritic-targeting element in CamKII $\alpha$ mRNA resulted in loss of dendritic localization of the mRNA and a reduction, but not elimination, of the protein at synapses [10], suggesting that CamKII $\alpha$ protein synthesized in the cell body can find its way to synapses, albeit at a lower level. However, such a decrease in synaptic CamKII $\alpha$ protein level and/or lack of activity-dependent translation of the CamKII $\alpha$ mRNA at synapses were sufficient to cause defects in synaptic plasticity and memory consolidation $[10]$, suggesting that these redundant targeting mechanisms are important.

\section{New classes of messages in dendrites}

Previous studies have revealed that mRNAs encoding receptors, cytoskeleton-interacting proteins, and signaling molecules are targeted to the dendrite of mature neurons in rodents [12,13]. In addition, Moccia et al. have identified 18 messages in Aplysia neurites that fall into the categories of cytoskeleton, translation, transmitter, and adhesion [16]. We find new classes of mRNAs involved in membrane trafficking and protein degradation are also present in dendrites. Our results show that a broad range of proteins can be synthesized in the dendrite, not only those critical for regulating the structural and electrophysiological properties of the synapse, but also others that play more common roles such as protein degradation. We believe that not every dendritic mRNA is tightly regulated by synaptic activity, and some of these messages may be transported because of efficiency rather than necessity, since it may be more efficient to transport mRNAs that each can be used to synthesize multiple copies of the protein.

We were surprised by the finding of ribosomal protein mRNAs in dendrites, even though it is in agreement with earlier findings of these messages in synaptosome preparations and in Aplysia neurites [16,72]. We are not certain why these messages are present in dendrites. One possibility is that locally synthesized ribosomal proteins are used for ribosomal protein add-on or replacement in dendrites, as suggested by Moccia et al. [16]. Although Moccia et al. have emphasized on its potential role in regulating ribosomal activity, we suggest that ribosomal protein replacement could also function in ribosome repair. We know that ribosome assembly is a complex process that involves the addition of a large number of ribosomal proteins to ribosomal RNAs [71], but little is known about what happens if one of these ribosomal proteins gets damaged. Is the whole ribosome then targeted for degradation, or can it be rescued by replacing the damaged protein? The pres- 
ence of ribosomal protein mRNAs in dendrites suggests that the later possibility could be true.

\section{Punctate staining and RNA granules}

It has been suggested that dendritic RNA may be transported in a very large form of ribonucleoprotein (RNP) complex called RNA granule $[52,53]$. In addition to the mRNA cargos, RNA granules also contain ribosome, translation factors, RNA-binding proteins, and molecular motors [52-56,74]. Movements of granule-like structures that contain staufen and FMRP have been visualized in the processes of living neurons [54,55,74]. We have observed punctate staining in the dendritic lamina of hippocampus after in situ hybridization using digoxigenlabeled ribo-probes for several mRNAs, including Arc. Punctate staining patterns of the Arc mRNA were also evident following different stimulation paradigms by Steward et al [75]. It is possible that these punctate staining patterns are related to RNA granules. However, in situ hybridization using a $\mathrm{BC} 1$-specific probe also showed discontinued (punctate) labeling patterns in the dendrite of cultured neurons [76], even though BC1 RNA did not cosediment with RNA granules on a sucrose gradient [53]. These results suggest that these puncta could also represent RNA-rich pockets in dendrites that are separated by regions that lack RNA, e.g. membranous structures such as the trans-Golgi network. A possible correlation between the punctate staining patterns and RNA granules has to be further investigated by more detailed co-localization studies of dendritic mRNAs and other components of RNA granules, either in neurons or on a sucrose gradient.

\section{Conclusion}

We have identified 154 dendrite-enriched mRNA candidates in rodent hippocampal neurons. Our results suggest that dendritic mRNAs encode diversified functionalities in neurons.

\section{Methods}

\section{Dissecting apical dendrites of rat hippocampal CAI pyramidal neurons}

Ten 6-8 week-old male Sprague-Dawley rats (Hilltop Lab Animals, Scottsdale, PA) were euthanized via carbon dioxide inhalation. Hippocampi were dissected out, cut into $300 \mu \mathrm{m}$ coronal sections, and submerged in RNAlater solution (Ambion, Inc., Austin, TX) in order to stabilize RNA during dissection. Cell nuclei were stained with $5 \mu \mathrm{M}$ SYTO 24 (Molecular Probes, Inc., Eugene, OR) to guide the dissection and to avoid contamination from cell bodies. CA1 stratum radiatum and the corresponding stratum pyramidale were dissected under a dissecting microscope with a UV light source. Only slices with tight organization of stratum pyramidale and little nuclear staining in stratum radiatum were used. Cuts were made above the lacu- nosum-moleculare layer to avoid scattered cell bodies from this region.

\section{Probe preparation and microarray analysis}

Dissected stratum radiatum and stratum pyramidale from 10 individual rats were pulled for RNA extraction using an RNeasy Protect Mini Kit from Qiagen (Valencia, CA). The integrity of RNA samples was examined using a Bioanalyzer (Agilent Technologies, Palo Alto, CA). Five hundred nanogram of each RNA sample was reverse-transcribed using a T7 promoter-conjugated oligo-dT primer, linearamplified and labeled with either Cyanine 3 - CTP or Cyanine 5 - CTP using a Low RNA Input Fluorescent Linear Amplification Kit (Agilent Technologies, Palo Alto, CA). Equal amounts of Cy3 and Cy5-labeled cRNA probes were mixed, and hybridized to a set of five replicas of a $22 \mathrm{~K}$ rat oligonucleotide microarray (Agilent Technologies, Palo Alto, CA) following the instructions supplied by the manufacturer. The resulting slides were scanned using a microarray scanner. Feature extraction, including standardization of signal intensity, background correction, and statistical analyses, were performed using Agilent's Feature Extraction Image Analysis Software following protocols from the manufacturer. Data from each individual array were compared and further analyzed using the error model of the Resolver software (Rosetta, Inc., Seattle, WA) to generate the final result. Messages that have at least 2-fold enrichment in the dendritic fraction over the cell body fraction were annotated using the GO_function and YPD_function databases in addition to the Agilent annotation. Each entry was then compared with published literatures and sorted into various groups based on its potential function. Entries that are likely resulted from glial and interneuron contaminations were removed from the list.

\section{RNA in situ hybridization}

Gene accession numbers were used to download the cDNA sequences from Genebank. Primers were designed to amplify 250-450 bp cDNA fragments from rat brain RNA by RT-PCR. The resulting PCR fragments were cloned into the pCRII-TOPO vector using a TOPO TA cloning kit (Invitrogen, Carlsbad, CA). The identity of each clone was confirmed by sequencing, and plasmid DNA was used to generate digoxigen-labeled sense and antisense riboprobes through in vitro run-off transcription. A spinophilin cDNA clone was received as a gift from Dr. Patrick Allen, and was used to generate spinophilin-specific probes. Four to six week-old male Sprague-Dawley rats (Hilltop Lab Animals, Scottsdale, PA) were treated with or without subcutaneous injection of $25 \mathrm{mg}$ kainic acid (Sigma-Aldrich, St. Louis, MO) per kg of body weight. Fresh-frozen brains were cut into $20 \mu \mathrm{m}$ coronal sections and hybridized according to the published protocol with modifications [77]. 


\section{List of abbreviations}

MAP2: Microtubule associated protein 2

EEF1A: eukaryotic translation elongation factor 1 alpha

CaMKII : calcium/calmodulin-dependent protein kinase (CaM kinase) II alpha

EST: expressed sequence tag

GPCR: G protein-coupled receptor

PKA: cAMP-dependent protein kinase

\section{Authors' contributions}

JZ carried out experimental design, dissection, sample preparation, and microarray hybridization (with the help of LMB). JZ also carried out in situ hybridization, literature search, and manuscript preparation. TZ carried out gene annotation and functional database search. LMB helped with microarray hybridization, and carried out microarray scanning, data processing, and statistical analyses. This study was conceived by JZ.

\section{Additional material}

\section{Additional File 1}

An Excel file containing the complete list of 154 dendritic mRNA candidates. Each sequence was annotated with three databases, and subjected to literature search. Relevant PubMed IDs were also included.

Click here for file

[http://www.biomedcentral.com/content/supplementary/14712202-7-17-S1.xls]

\section{Additional File 2}

Original results from three microarrays, including gene ID, log ratio, log ratio error, P value, and signal intensities, signal error, mean signal, median signal, and pixel S Dev for both red and green signals. Click here for file

[http://www.biomedcentral.com/content/supplementary/14712202-7-17-S2.xls]

\section{Additional File 3}

Original results from three microarrays, including gene ID, log ratio, log ratio error, P value, and signal intensities, signal error, mean signal, median signal, and pixel S Dev for both red and green signals.

Click here for file

[http://www.biomedcentral.com/content/supplementary/14712202-7-17-S3.xls]

\section{Additional File 4}

Original results from three microarrays, including gene ID, log ratio, log ratio error, $P$ value, and signal intensities, signal error, mean signal, median signal, and pixel S Dev for both red and green signals.

Click here for file

[http://www.biomedcentral.com/content/supplementary/14712202-7-17-S4.xls]

\section{Additional File 5}

Final processed data for all $22 \mathrm{~K}$ entries, including signal intensities, log ratio, log ratio error, and fold change.

Click here for file

[http://www.biomedcentral.com/content/supplementary/14712202-7-17-S5.xls]

\section{Acknowledgements}

We would like to thank Dr. Patrick Allen for spinophilin cDNA, Dr. Christopher Pittenger for helping with the dissection, and Drs. Eric Kandel, Henri Tiedge, Todd Sacktor for helpful discussion of the manuscript. JZ is a BIRCWH scholar sponsored by a NIH grant (HD43428).

\section{References}

I. Steward O, Levy WB: Preferential localization of polyribosomes under the base of dendritic spines in granule cells of the dentate gyrus. J Neurosci 1982, 2:284-291.

2. Feig S, Lipton P: Pairing the cholinergic agonist carbachol with patterned Schaffer collateral stimulation initiates protein synthesis in hippocampal CAI pyramidal cell dendrites via a muscarinic, NMDA-dependent mechanism. J Neurosci 1993, 13:1010-1021.

3. Ouyang Y, Kantor D, Harris KM, Schuman EM, Kennedy MB: Visualization of the distribution of autophosphorylated calcium/ calmodulin-dependent protein kinase II after tetanic stimulation in the CAI area of the hippocampus. J Neurosci 1997. 17:5416-5427.

4. Ouyang Y, Rosenstein A, Kreiman G, Schuman EM, Kennedy MB: Tetanic stimulation leads to increased accumulation of $\mathrm{Ca}(2+) / c a l m o d u l i n-d e p e n d e n t$ protein kinase II via dendritic protein synthesis in hippocampal neurons. I Neurosci 1999, 19:7823-7833.

5. Weiler IJ, Irwin SA, Klintsova AY, Spencer CM, Brazelton AD, Miyashiro K, Comery TA, Patel B, Eberwine J, Greenough WT: Fragile X mental retardation protein is translated near synapses in response to neurotransmitter activation. Proc Natl Acad Sci U S A 1997, 94:5395-5400.

6. Weiler IJ, Spangler CC, Klintsova AY, Grossman AW, Kim SH, Bertaina-Anglade $\mathrm{V}$, Khaliq $\mathrm{H}$, de Vries FE, Lambers FA, Hatia F, Base CK, Greenough WT: Fragile $\mathbf{X}$ mental retardation protein is necessary for neurotransmitter-activated protein translation at synapses. Proc Natl Acad Sci U S A 2004, I O I: 17504- 7509.

7. Yin Y, Edelman GM, Vanderklish PW: The brain-derived neurotrophic factor enhances synthesis of Arc in synaptoneurosomes. Proc Natl Acad Sci U S A 2002, 99:2368-2373.

8. Todd PK, Mack KJ, Malter JS: The fragile $\mathbf{X}$ mental retardation protein is required for type-I metabotropic glutamate receptor-dependent translation of PSD-95. Proc Natl Acad Sci U S A 2003, 100:14374-14378.

9. Martin KC, Casadio A, Zhu H, Yaping E, Rose JC, Chen M, Bailey CH, Kandel ER: Synapse-specific, long-term facilitation of aplysia sensory to motor synapses: a function for local protein synthesis in memory storage. Cell 1997, 91:927-938.

10. Miller S, Yasuda M, Coats JK, Jones Y, Martone ME, Mayford M: Disruption of dendritic translation of CaMKIlalpha impairs stabilization of synaptic plasticity and memory consolidation. Neuron 2002, 36:507-519.

II. Eberwine J, Miyashiro K, Kacharmina JE, Job C: Local translation of classes of mRNAs that are targeted to neuronal dendrites. Proc Natl Acad Sci U S A 200I, 98:7080-7085.

12. Steward O, Schuman EM: Protein synthesis at synaptic sites on dendrites. Annu Rev Neurosci 200I, 24:299-325.

13. Steward O, Schuman EM: Compartmentalized synthesis and degradation of proteins in neurons. Neuron 2003, 40:347-359.

14. Eberwine J, Belt B, Kacharmina JE, Miyashiro K: Analysis of subcellularly localized mRNAs using in situ hybridization, mRNA amplification, and expression profiling. Neurochem Res 2002, 27:1065-1077. 
15. Miyashiro K, Dichter M, Eberwine J: On the nature and differential distribution of mRNAs in hippocampal neurites: implications for neuronal functioning. Proc Natl Acad Sci U S A 1994, 91:10800-10804.

16. Moccia R, Chen D, Lyles V, Kapuya E, E Y, Kalachikov S, Spahn CM, Frank J, Kandel ER, Barad M, Martin KC: An unbiased cDNA library prepared from isolated Aplysia sensory neuron processes is enriched for cytoskeletal and translational mRNAs. J Neurosci 2003, 23:9409-94I7.

17. Garner CC, Tucker RP, Matus A: Selective localization of messenger RNA for cytoskeletal protein MAP2 in dendrites. Nature 1988, 336:674-677.

18. Geinisman Y: Structural synaptic modifications associated with hippocampal LTP and behavioral learning. Cereb Cortex 2000, 10:952-962.

19. Marrone DF, Petit TL: The role of synaptic morphology in neural plasticity: structural interactions underlying synaptic power. Brain Res Brain Res Rev 2002, 38:29I-308.

20. Kim JH, Udo H, Li HL, Youn TY, Chen M, Kandel ER, Bailey CH: Presynaptic activation of silent synapses and growth of new synapses contribute to intermediate and long-term facilitation in Aplysia. Neuron 2003, 40:15 I- 165

21. Colicos MA, Collins BE, Sailor MJ, Goda Y: Remodeling of synaptic actin induced by photoconductive stimulation. Cell 200I, 1 07:605-6I6.

22. Udo H, Jin I, Kim JH, Li HL, Youn T, Hawkins RD, Kandel ER, Bailey $\mathrm{CH}$ : Serotonin-induced regulation of the actin network for learning-related synaptic growth requires Cdc42, N-WASP, and PAK in Aplysia sensory neurons. Neuron 2005, 45:887-90 I.

23. Huh GS, Boulanger LM, Du H, Riquelme PA, Brotz TM, Shatz C]: Functional requirement for class I MHC in CNS development and plasticity. Science 2000, 290:2155-2I59.

24. Corriveau RA, Huh GS, Shatz C): Regulation of class I MHC gene expression in the developing and mature CNS by neural activity. Neuron 1998, 21:505-520.

25. Syken J, Shatz C]: Expression of $\mathbf{T}$ cell receptor beta locus in central nervous system neurons. Proc Natl Acad Sci U S A 2003, I 00: | 3048-|3053.

26. Berry FB, Brown IR: CaM I mRNA is localized to apical dendrites during postnatal development of neurons in the rat brain. J Neurosci Res 1996, 43:565-575.

27. Watson JB, Coulter PM, Margulies JE, de Lecea L, Danielson PE Erlander MG, Sutcliffe JG: G-protein gamma 7 subunit is selectively expressed in medium-sized neurons and dendrites of the rat neostriatum. I Neurosci Res 1994, 39: I08- I I6.

28. Dufner A, Thomas G: Ribosomal S6 kinase signaling and the control of translation. Exp Cell Res 1999, 253:100-109.

29. Allen PB, Ouimet CC, Greengard P: Spinophilin, a novel protein phosphatase I binding protein localized to dendritic spines. Proc Natl Acad Sci U S A 1997, 94:9956-9961.

30. Satoh A, Nakanishi H, Obaishi H, Wada M, Takahashi K, Satoh K, Hirao K, Nishioka H, Hata Y, Mizoguchi A, Takai Y: Neurabin-II/ spinophilin. An actin filament-binding protein with one pdz domain localized at cadherin-based cell-cell adhesion sites. Biol Chem 1998, 273:3470-3475.

31. Yan Z, Hsieh-Wilson L, Feng J, Tomizawa K, Allen PB, Fienberg AA, Nairn AC, Greengard P: Protein phosphatase I modulation of neostriatal AMPA channels: regulation by DARPP-32 and spinophilin. Nat Neurosci 1999, 2:13-17.

32. Morishita W, Connor JH, Xia H, Quinlan EM, Shenolikar S, Malenka RC: Regulation of synaptic strength by protein phosphatase I. Neuron 2001, 32:1133-1|48.

33. Feng J, Yan Z, Ferreira A, Tomizawa K, Liauw JA, Zhuo M, Allen PB, Ouimet CC, Greengard P: Spinophilin regulates the formation and function of dendritic spines. Proc Natl Acad Sci U S A 2000, 97:9287-9292

34. Smith FD, Oxford GS, Milgram SL: Association of the D2 dopamine receptor third cytoplasmic loop with spinophilin, a protein phosphatase-I-interacting protein. J Biol Chem 1999 274: $19894-19900$

35. Richman JG, Brady AE, Wang Q, Hensel JL, Colbran RJ, Limbird LE: Agonist-regulated Interaction between alpha2-adrenergic receptors and spinophilin. J Biol Chem 200I, 276:I5003-I5008.

36. Stephens DJ, Banting G: Direct interaction of the trans-Golgi network membrane protein, TGN38, with the F-actin binding protein, neurabin. J Biol Chem 1999, 274:30080-30086.
37. Ide N, Hata Y, Hirao K, Irie M, Deguchi M, Yao I, Satoh A, Wada M, Takahashi K, Nakanishi H, Takai Y: Interaction of rat lin- 10 with brain-enriched F-actin-binding protein, neurabin-II/spinophilin. Biochem Biophys Res Commun 1998, 244:258-262.

38. Wang Q, Zhao J, Brady AE, Feng J, Allen PB, Lefkowitz RJ, Greengard $P$, Limbird LE: Spinophilin blocks arrestin actions in vitro and in vivo at $\mathbf{G}$ protein-coupled receptors. Science 2004 304: 1940-1944

39. Giustetto M, Hegde AN, Si K, Casadio A, Inokuchi K, Pei W, Kandel ER, Schwartz JH: Axonal transport of eukaryotic translation elongation factor I alpha mRNA couples transcription in the nucleus to long-term facilitation at the synapse. Proc Natl Acad Sci U S A 2003, I00:13680-13685.

40. Sung YJ, Dolzhanskaya N, Nolin SL, Brown T, Currie JR, Denman RB: The fragile $X$ mental retardation protein FMRP binds elongation factor IA mRNA and negatively regulates its translation in vivo. J Biol Chem 2003, 278: I5669-I5678.

4I. Huang F, Chotiner JK, Steward O: The mRNA for elongation factor I alpha is localized in dendrites and translated in response to treatments that induce long-term depression. I Neurosci 2005, 25:7199-7209.

42. Lehmann R, Nusslein-Volhard C: The maternal gene nanos has a central role in posterior pattern formation of the Drosophila embryo. Development I99|, I | 2:679-69|

43. Wharton RP, Sonoda J, Lee T, Patterson M, Murata Y: The Pumilio RNA-binding domain is also a translational regulator. Mol Cell 1998, I:863-872.

44. Parisi M, Lin $\mathrm{H}$ : Translational repression: a duet of Nanos and Pumilio. Curr Biol 2000, I 0:R8I-3.

45. Sonoda J, Wharton RP: Recruitment of Nanos to hunchback mRNA by Pumilio. Genes Dev 1999, I3:2704-2712.

46. Asaoka-Taguchi M, Yamada M, Nakamura A, Hanyu K, Kobayashi S: Maternal Pumilio acts together with Nanos in germline development in Drosophila embryos. Nat Cell Biol 1999, I: 43 I -437.

47. Nakahata S, Kotani T, Mita K, Kawasaki T, Katsu Y, Nagahama Y, Yamashita $M$ : Involvement of Xenopus Pumilio in the translational regulation that is specific to cyclin $B I$ mRNA during oocyte maturation. Mech Dev 2003, I 20:865-880.

48. Dubnau J, Chiang AS, Grady L, Barditch J, Gossweiler S, McNeil J, Smith P, Buldoc F, Scott R, Certa U, Broger C, Tully T: The staufen/ pumilio pathway is involved in Drosophila long-term memory. Curr Biol 2003, I 3:286-296.

49. Menon KP, Sanyal S, Habara Y, Sanchez R, Wharton RP, Ramaswami $M$, Zinn K: The translational repressor Pumilio regulates presynaptic morphology and controls postsynaptic accumulation of translation factor elF-4E. Neuron 2004, 44:663-676.

50. Ye B, Petritsch C, Clark IE, Gavis ER, Jan LY, Jan YN: Nanos and Pumilio are essential for dendrite morphogenesis in Drosophila peripheral neurons. Curr Biol 2004, I 4:3 |4-32I.

5I. Mee CJ, Pym EC, Moffat KG, Baines RA: Regulation of neuronal excitability through pumilio-dependent control of a sodium channel gene. I Neurosci 2004, 24:8695-8703.

52. Knowles RB, Sabry JH, Martone ME, Deerinck TJ, Ellisman MH, Bassell G], Kosik KS: Translocation of RNA granules in living neurons. J Neurosci 1996, 16:78|2-7820.

53. Krichevsky AM, Kosik KS: Neuronal RNA granules: a link between RNA localization and stimulation-dependent translation. Neuron 200I, 32:683-696.

54. Kohrmann M, Luo M, Kaether C, DesGroseillers L, Dotti CG, Kiebler MA: Microtubule-dependent recruitment of Staufen-green fluorescent protein into large RNA-containing granules and subsequent dendritic transport in living hippocampal neurons. Mol Biol Cell 1999, 10:2945-2953.

55. De Diego Otero Y, Severijnen LA, van Cappellen G, Schrier M, Oostra B, Willemsen $\mathrm{R}$ : Transport of fragile $\mathbf{X}$ mental retardation protein via granules in neurites of PCI 2 cells. Mol Cell Biol 2002, 22:8332-834I

56. Kanai Y, Dohmae N, Hirokawa N: Kinesin transports RNA: isolation and characterization of an RNA-transporting granule. Neuron 2004, 43:513-525.

57. Hegde AN, Goldberg AL, Schwartz JH: Regulatory subunits of cAMP-dependent protein kinases are degraded after conjugation to ubiquitin: a molecular mechanism underlying longterm synaptic plasticity. Proc Natl Acad Sci U S A 1993 , 90:7436-7440. 
58. Hegde AN, Inokuchi K, Pei W, Casadio A, Ghirardi M, Chain DG, Martin KC, Kandel ER, Schwartz JH: Ubiquitin C-terminal hydrolase is an immediate-early gene essential for long-term facilitation in Aplysia. Cell 1997, 89: I I5-I26.

59. Chain DG, Casadio A, Schacher S, Hegde AN, Valbrun M, Yamamoto N, Goldberg AL, Bartsch D, Kandel ER, Schwartz JH: Mechanisms for generating the autonomous cAMP-dependent protein kinase required for long-term facilitation in Aplysia. Neuron 1999, 22: I 147-156.

60. Zhao Y, Hegde AN, Martin KC: The ubiquitin proteasome system functions as an inhibitory constraint on synaptic strengthening. Curr Biol 2003, 13:887-898.

61. Xu J, Taya S, Kaibuchi K, Arnold AP: Spatially and temporally specific expression in mouse hippocampus of Usp9x, a ubiquitinspecific protease involved in synaptic development. J Neurosci Res 2005.

62. Kishino T, Lalande M, Wagstaff J: UBE3A/E6-AP mutations cause Angelman syndrome. Nat Genet 1997, 15:70-73.

63. Jiang $\mathrm{YH}$, Armstrong D, Albrecht $U$, Atkins CM, Noebels JL, Eichele G, Sweatt JD, Beaudet AL: Mutation of the Angelman ubiquitin ligase in mice causes increased cytoplasmic p53 and deficits of contextual learning and long-term potentiation. Neuron 1998, 21:799-8| I.

64. Hicke L, Dunn R: Regulation of membrane protein transport by ubiquitin and ubiquitin-binding proteins. Annu Rev Cell Dev Biol 2003, 19:14|-|72.

65. Patrick GN, Bingol B, Weld HA, Schuman EM: Ubiquitin-mediated proteasome activity is required for agonist-induced endocytosis of GluRs. Curr Biol 2003, 13:2073-208I.

66. Bailey $\mathrm{CH}$, Chen M, Keller F, Kandel ER: Serotonin-mediated endocytosis of apCAM: an early step of learning-related synaptic growth in Aplysia. Science 1992, 256:645-649.

67. Mayford M, Barzilai A, Keller F, Schacher S, Kandel ER: Modulation of an NCAM-related adhesion molecule with long-term synaptic plasticity in Aplysia. Science 1992, 256:638-644.

68. Malinow R, Malenka RC: AMPA receptor trafficking and synaptic plasticity. Annu Rev Neurosci 2002, 25: 103-126.

69. Walikonis RS, Jensen ON, Mann M, Provance DWJ, Mercer JA, Kennedy MB: Identification of proteins in the postsynaptic density fraction by mass spectrometry. I Neurosci 2000, 20:4069-4080.

70. Ohashi S, Koike K, Omori A, Ichinose S, Ohara S, Kobayashi S, Sato TA, Anzai K: Identification of mRNA/protein (mRNP) complexes containing Puralpha, $m$ Staufen, fragile $X$ protein, and myosin $\mathrm{Va}$ and their association with rough endoplasmic reticulum equipped with a kinesin motor. J Biol Chem 2002, 277:37804-378I0.

7I. Fromont-Racine M, Senger B, Saveanu C, Fasiolo F: Ribosome assembly in eukaryotes. Gene 2003, 313:17-42.

72. Sung YJ, Weiler IJ, Greenough WT, Denman RB: Selectively enriched mRNAs in rat synaptoneurosomes. Brain Res Mol Brain Res 2004, I 26:81-87.

73. Grossman SD, Hsieh-Wilson LC, Allen PB, Nairn AC, Greengard P: The actin-binding domain of spinophilin is necessary and sufficient for targeting to dendritic spines. Neuromolecular Med 2002, 2:61-69.

74. Antar LN, Afroz R, Dictenberg JB, Carroll RC, Bassell GJ: Metabotropic glutamate receptor activation regulates fragile $x$ mental retardation protein and FMRI mRNA localization differentially in dendrites and at synapses. J Neurosci 2004, 24:2648-2655

75. Steward O, Wallace CS, Lyford GL, Worley PF: Synaptic activation causes the mRNA for the IEG Arc to localize selectively near activated postsynaptic sites on dendrites. Neuron 1998, 2I:74I-75I.

76. Muslimov IA, Banker G, Brosius J, Tiedge H: Activity-dependent regulation of dendritic BCI RNA in hippocampal neurons in culture. / Cell Biol I998, I4I:1601-161 I.

77. Schaeren-Wiemers N, Gerfin-Moser A: A single protocol to detect transcripts of various types and expression levels in neural tissue and cultured cells: in situ hybridization using digoxigenin-labelled cRNA probes. Histochemistry 1993, 100:431-440.
Publish with Bio Med Central and every scientist can read your work free of charge

"BioMed Central will be the most significant development for disseminating the results of biomedical research in our lifetime. "

Sir Paul Nurse, Cancer Research UK

Your research papers will be:

- available free of charge to the entire biomedical community

- peer reviewed and published immediately upon acceptance

- cited in PubMed and archived on PubMed Central

- yours - you keep the copyright
BioMedcentral 